\title{
Functional impact of pulmonary hypertension due to hypoventilation and changes under noninvasive ventilation
}

\author{
Matthias Held, Johanna Walthelm, Stefan Baron, Christine Roth and \\ Berthold Jany
}

Affiliation: Dept of Internal Medicine, Medical Mission Hospital, Academic Teaching Hospital, Julius Maximilian University of Würzburg, Würzburg, Germany.

Correspondence: M. Held, Medical Mission Hospital, Academic Teaching Hospital, Julius Maximilian University of Würzburg, Salvatorstrasse 7, 97074 Würzburg, Germany. E-mail: Matthias.heldamissioklinik.de

ABSTRACT We aimed to characterise the association of pulmonary hypertension due to hypoventilation and exercise capacity, and the haemodynamic and functional changes under noninvasive ventilation.

A retrospective analysis was carried out to assess haemodynamics and functional capacity in 18 patients with daytime pulmonary hypertension, due to hypoventilation, at baseline and after 3 months of noninvasive ventilation.

Patients presented with a mean \pm SD pulmonary artery pressure of $49 \pm 13 \mathrm{mmHg}$, preserved cardiac index $\left(3.2 \pm 0.66 \mathrm{~L} \cdot \mathrm{min}^{-1} \cdot \mathrm{m}^{-2}\right), 6$-min walking distance of $303 \pm 134 \mathrm{~m}$ and severely elevated N-terminal pro-brain natriuretic peptide (NT-proBNP) levels. Mean pulmonary artery pressure correlated negatively with maximum work rate $(\mathrm{R}=-0.72 ; \mathrm{p}=0.03)$ and 6 -min walking distance $(\mathrm{R}=-0.62 ; \mathrm{p}=0.01)$. Following noninvasive ventilation we found a significant reduction of mean pulmonary artery pressure $(-18 \mathrm{mmHg}$; $\mathrm{p}<0.001)$ and NT-proBNP levels $\left(-2110 \mathrm{pg} \cdot \mathrm{mL}^{-1} ; \mathrm{p}=0.001\right)$, and improvement in the 6-min walking distance $(+66 \mathrm{~m} ; \mathrm{p}=0.008)$ and maximum work rate $(+18 \mathrm{~W} ; \mathrm{p}=0.028)$. Changes in work rate correlated inversely with pulmonary artery pressure $(\mathrm{R}=-0.75 ; \mathrm{p}=0.031)$.

In this specific cohort with hypoventilation and severe pulmonary hypertension, pulmonary hypertension was associated with reduced exercise capacity. Following noninvasive ventilation, haemodynamics and exercise capacity improved significantly.

@ERSpublications

Pulmonary hypertension due to alveolar hypoventilation is associated with functional impairment and improved by NIPPV http://ow.ly/pMYlL

For editorial comments see page 12.

This article has supplementary material available from www.erj.ersjournals.com

Received: Sept 172012 | Accepted after revision: May 142013 | First published online: May 302013

Conflict of interest: Disclosures can be found alongside the online version of this article at www.erj.ersjournals.com

Copyright @ERS 2014 


\section{Introduction}

Interest in severe obesity hypoventilation syndrome (OHS) is growing because of its increasing incidence and associated high morbidity and mortality [1]. The rising number of patients with severe pulmonary hypertension $(\mathrm{PH})$ due to alveolar hypoventilation is of particular concern. In obstructive sleep apnoea (OSA) and overlap syndrome, $\mathrm{PH}$ is rare and pulmonary artery pressure (PAP) is only mildly elevated. By contrast, in alveolar hypoventilation, $\mathrm{PH}$ is more frequently observed and of higher severity [2-6]. The pathogenesis of $\mathrm{PH}$ in patients with alveolar hypoventilation is still unclear. Hypoxia may lead to an increase in PAP, but significant interspecies and, in humans, interindividual differences in acute pulmonary vasoconstriction have been reported [3, 7-9]. Although carbon dioxide $\left(\mathrm{CO}_{2}\right)$ and acidosis influence pulmonary vasoconstriction, not all patients with hypoventilation and hypercapnia develop PH [10, 11]. A high prevalence of pulmonary arterial and pulmonary venous hypertension was reported in obese patients in an autopsy study [12]. The positive correlation between body weight and PAP in OSA underscores the possible influence of obesity on pulmonary haemodynamics [3]. However, PH does not occur in all obese patients [6]. The extent of functional impact of $\mathrm{PH}$ in patients with hypoventilation is still unknown.

Current guidelines recommend treatment of the underlying disease for $\mathrm{PH}$ occurring due to lung diseases and ventilatory disorders $[13,14]$. Oxygen administration alone stabilised, but did not reduce PAP in patients with chronic obstructive pulmonary disease (COPD) [15], and failed to improve haemodynamics in patients with chest wall diseases and OHS [16]. Following surgically induced weight loss, a long-term decline in PAP has been shown [6, 17]. Despite improving blood gases in patients with OSA and hypercapnia [18], application of continuous positive airway pressure (CPAP) had no effect on pulmonary haemodynamics in patients with OSA [19]. Noninvasive positive-pressure ventilation (NIPPV) in patients with OHS improved blood gases [20-23], vital capacity, expiratory reserve volume [21, 23], daytime sleepiness and dyspnoea [24, 25]. Moreover, long-term NIPPV has been found to increase serum leptin levels [26]. Patients with OSA and hypercapnia exhibited an increased chemo-responsiveness to $\mathrm{CO}_{2}$ and hypoxaemia under CPAP $[23,26,27]$. NIPPV was shown to have a positive effect on the haemodynamics of patients with alveolar hypoventilation due to thoracic restriction [28]. However, the effect of NIPPV on PH and exercise capacity of obese patients with alveolar hypoventilation, has not been studied.

The objective of this research was to study haemodynamics in a cohort of patients with daytime $\mathrm{PH}$ and alveolar hypoventilation, as well as to define the impact of $\mathrm{PH}$ on functional capacity. Furthermore, we aimed to analyse the effect of NIPPV on haemodynamics and functional capacity.

\section{Methods}

Study subjects were recruited from all consecutive 160 patients who presented to the Medical Mission Hospital (Würzburg, Germany) between October 2009 and July 2011 for further evaluation and treatment of PH. 18 patients met the criteria of daytime $\mathrm{PH}$ and alveolar hypoventilation and were retrospectively analysed (fig. 1). Patients with confirmed PH (mean PAP (mPAP) at rest $\geqslant 25 \mathrm{mmHg}$ or $\mathrm{mPAP}$ at rest $<25 \mathrm{mmHg}$ and mPAP at exercise $\geqslant 50 \mathrm{mmHg}$ or, if right heart catheterisation could not be performed, an echocardiographic systolic $\mathrm{PAP} \geqslant 50 \mathrm{mmHg}$ at rest and daytime $\mathrm{CO}_{2}$ of $\geqslant 45 \mathrm{mmHg}$ or a mean night-time $\mathrm{CO}_{2}$ of $\geqslant 55 \mathrm{mmHg}$ ) were included. Exclusion criteria were chronic thromboembolic pulmonary hypertension or pulmonary arterial hypertension $(\mathrm{PAH})$ associated diseases such as cardiac shunt, collagen vascular disease, porto-pulmonary hypertension, HIV-associated PAH, and drug- and toxin-induced PAH. Written informed consent was obtained from all patients prior to analysis. The study was approved by the Ethics Committee of the Medical Faculty of the Julius Maximilian University Würzburg (Würzburg, Germany).

Diagnosis was established according to current guidelines [13]. Echocardiography (Vivid7; GE Medical Systems, Solingen, Germany) was performed to measure systolic right ventricular pressure, and right and left ventricular function, as well as to rule out a cardiac shunt and significant valvular pathology. ECG (ECG 550020728; GE Medical Systems) was also performed. Body plethysmography (Masterscreen Body/Diff; CareFusion, Höchberg, Germany) was performed according to the European Respiratory Society statement [29]. Inspiratory mouth pressures were measured as described previously [30]. Computed tomography (Activion 16; Toshiba Medical Systems, Neuss, Germany) was conducted to rule out structural lung disease. A ventilation/perfusion scan (Technegas-Generator (Tetley Medical Limited, Lucas Heights, Australia) and E Cam Variable (Siemens Medical Solutions Inc., Hoffman Estates, IL, USA)) was performed to rule out pulmonary embolism. Blood gases were measured at rest and under exercise (ABL 800 Basic; Radiometer, Cadolzburg, Germany). Functional capacity was characterised by a 6-min walk test, carried out according to the American Thoracic Society (ATS) statement [31]. In capable patients, a bicycle cardiopulmonary exercise test (Masterscreen CPX (CareFusion) and E-bike basic PC plus (GE Medical Systems)) was performed according to the ATS and the American College of Chest Physicians (ACCP) statement [32]. 


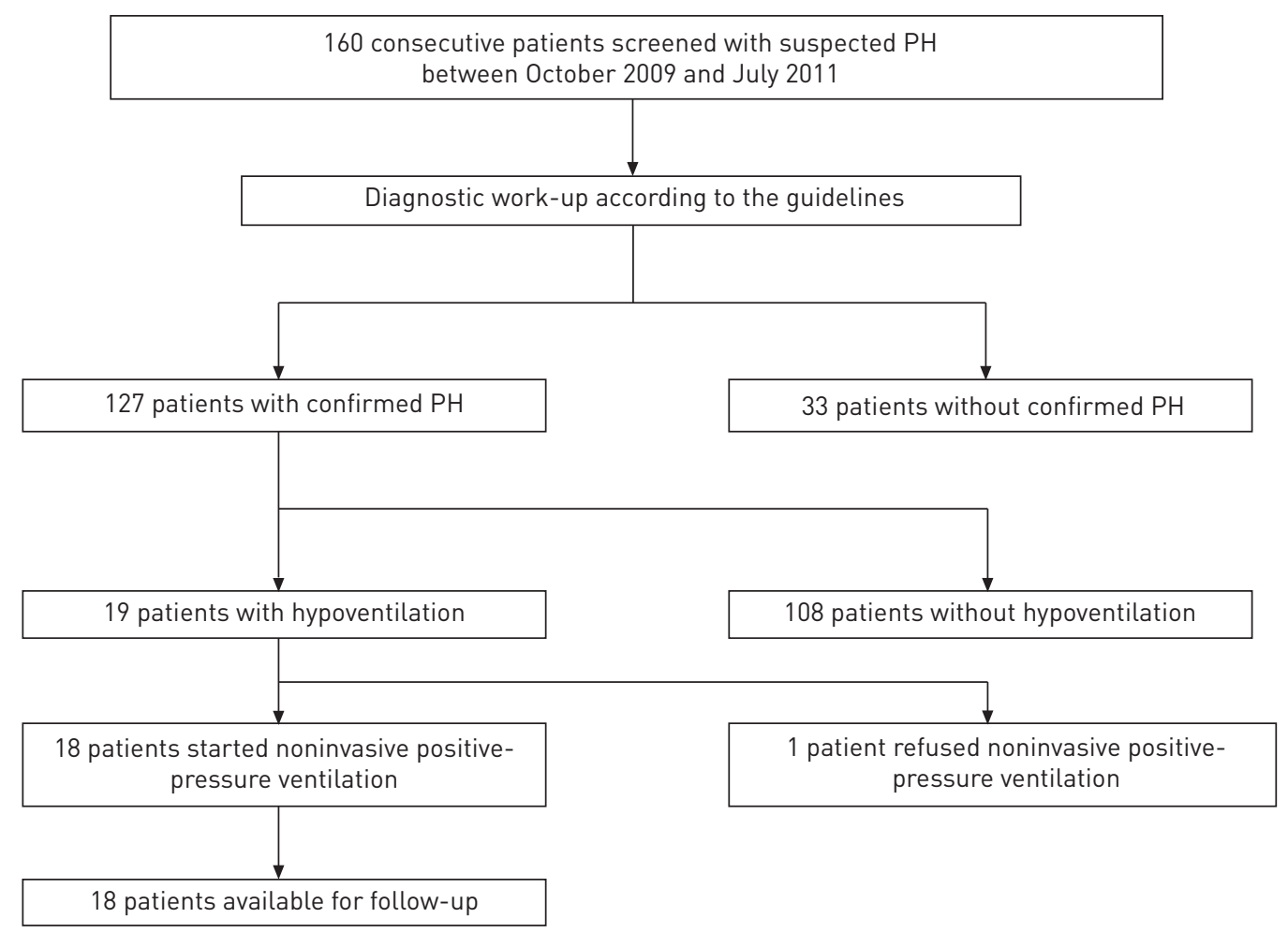

FIGURE 1 Patient selection for retrospective analysis of 18 patients with pulmonary hypertension (PH) and alveolar hypoventilation.

Daytime right heart catheterisation was performed according to the guidelines using a Swan-Ganz catheter (Smith Medical, Grasbrunn, Germany) [15]. Measurements were conducted with the monitor system (IntelliVue MP70 (M8007A); Philips Medizinsysteme, Böblingen, Germany). A night-time cardiorespiratory polygraphy, including measurement of nocturnal oxygen saturation and $\mathrm{CO}_{2}$ tension (Somnocheck (Weinmann, Hamburg, Germany) and TOSCA (Radiometer GmbH, Willich, Germany)) was performed according to the ACCP guidelines [33]. Serum levels of N-terminal pro-brain natriuretic peptide (NTproBNP) were measured by ECLIA (Elecys 2010; Roche Diagnostik, Mannheim, Germany).

All 18 patients with confirmed PH and alveolar hypoventilation were treated using noninvasive bi-level positive-pressure ventilation according to the guidelines of the German Respiratory Society [34] (using Harmony II (Respironics, Herrsching, Germany) or Stellar 150 (ResMed, Martinsried, Germany)). All patients were assessed by a routine follow-up 3 months after initiation of the ventilation therapy. The same diagnostic tests used at baseline were carried out during the follow-up.

Only the patients with data available at both baseline and the 3 month follow-up assessment were considered for analysing mean changes in each parameter. Statistical analyses were performed using Statistica (Version 10; StatSoft Inc., Tulsa, OK, USA). The mean and standard deviation were calculated. Correlations of the parameters were evaluated by Spearman test. Statistical significance was expressed as p-values with the Wilcoxon test and assumed if the $\mathrm{p}$-value was $<0.05$.

\section{Results}

\section{Baseline characteristics}

Patients were selected as shown in figure 1 . Table 1 and online supplementary tables $2-3$ show the characteristics of the 18 patients ( 11 females and seven males). Mean \pm SD age was $62 \pm 10$ years, body mass index (BMI) was $36.1 \pm 9.8 \mathrm{~kg} \cdot \mathrm{m}^{-2}$ and body weight was $104 \pm 30 \mathrm{~kg}$. 12 patients fulfilled the criteria of OHS. Three out of these 12 patients had concomitant COPD. In 5 patients COPD was the sole cause for hypoventilation.

Patients had a reduced vital capacity (VC) $(51 \pm 19 \%$ predicted), forced expiratory volume in $1 \mathrm{~s}(\mathrm{FEV} 1)$ $(43 \pm 18 \%$ pred), elevated residual volume (RV) $(167 \pm 77 \%$ pred) and a mean total lung capacity of $94 \pm 33 \%$ pred. The cohort showed daytime hypercapnia and hypoxaemia, which was aggravated at night-time. 
TABLE 1 Values at baseline and at follow-up after 3 months of noninvasive positive-pressure ventilation

\begin{tabular}{|c|c|c|c|c|c|}
\hline \multirow[t]{2}{*}{ Method/parameter } & \multicolumn{2}{|c|}{ Baseline } & \multicolumn{2}{|c|}{ Follow-up } & \multirow[t]{2}{*}{$\mathrm{p}$-value } \\
\hline & Subjects $n$ & Mean \pm SD & Subjects $n$ & Mean \pm SD & \\
\hline BMI & 18 & $36.1 \pm 9.8$ & 18 & $35.1 \pm 9$ & 0.14 \\
\hline \multicolumn{6}{|l|}{ Right heart catheterisation } \\
\hline sPAP mmHg & 17 & $71 \pm 18$ & 16 & $44 \pm 13$ & 0.001 \\
\hline mPAP mmHg & 17 & $49 \pm 13$ & 16 & $31 \pm 9$ & $<0.001$ \\
\hline $\mathrm{dPVG} \mathrm{mmHg}$ & 17 & $23 \pm 10$ & 16 & $14 \pm 4$ & $<0.001$ \\
\hline PVR dyn $\cdot s \cdot \mathrm{cm}^{-5}$ & 17 & $499 \pm 171$ & 16 & $292 \pm 108$ & $<0.001$ \\
\hline Cardiac index $\mathrm{L} \cdot \mathrm{min}^{-1} \cdot \mathrm{m}^{-2}$ & 17 & $3.2 \pm 0.7$ & 15 & $3.2 \pm 0.7$ & 0.807 \\
\hline RAP $\mathrm{mmHg}$ & 17 & $14 \pm 8$ & 15 & $8 \pm 3$ & $<0.01$ \\
\hline 6-min walking distance $\mathrm{m}$ & 17 & $303 \pm 133$ & 16 & $384 \pm 126$ & $<0.01$ \\
\hline \multicolumn{6}{|l|}{ Echocardiography } \\
\hline TAPSE mm & 18 & $18 \pm 5$ & 18 & $25 \pm 4$ & $<0.001$ \\
\hline \multicolumn{6}{|l|}{ Daytime blood gases } \\
\hline $\mathrm{PO}_{2}$ at rest $\mathrm{mmHg}$ & 17 & $56.4 \pm 14.4$ & 16 & $71.2 \pm 11.3$ & 0.01 \\
\hline $\mathrm{PCO}_{2}$ at rest $\mathrm{mmHg}$ & 17 & $52.2 \pm 5.8$ & 16 & $44.5 \pm 4$ & $<0.001$ \\
\hline $\mathrm{SpO}_{2}$ at rest $\%$ & 17 & $87 \pm 7$ & 16 & $94 \pm 3$ & $<0.01$ \\
\hline \multicolumn{6}{|l|}{ Night-time oximetry and capnometry } \\
\hline Mean night-time $\mathrm{CO}_{2} \mathrm{mmHg}$ & 17 & $61.8 \pm 7.7$ & 14 & $46.4 \pm 9$ & 0.001 \\
\hline Maximum night-time $\mathrm{CO}_{2} \mathrm{mmHg}$ & 17 & $72.7 \pm 10.6$ & 13 & $54.7 \pm 7.4$ & 0.002 \\
\hline Mean night-time $\mathrm{SpO}_{2} \%$ & 18 & $82 \pm 10$ & 16 & $94 \pm 3$ & 0.001 \\
\hline \multicolumn{6}{|l|}{ Cardiopulmonary exercise test } \\
\hline Maximum work rate $\mathrm{W}$ & 9 & $67 \pm 40$ & 9 & $85 \pm 32$ & 0.028 \\
\hline $\mathrm{V}^{\prime} \mathrm{O}_{2}$ peak $\%$ predicted & 9 & $65 \pm 25$ & 9 & $71 \pm 23$ & 0.24 \\
\hline NT-proBNP pg $\cdot \mathrm{mL}^{-1}$ & 14 & $2403 \pm 2082$ & 13 & $377 \pm 416$ & 0.001 \\
\hline
\end{tabular}

Only the patients with data available at both baseline and 3 month follow-up were considered for analysing mean changes in each parameter. BMI: body mass index; sPAP: systolic pulmonary arterial pressure (PAP); mPAP: mean PAP; dPAP: diastolic PAP; PAWP: pulmonary artery wedge pressure; dPVG: diastolic pulmonary vascular gradient; PVR: pulmonary vascular resistance; RAP: right atrial pressure; EF: ejection fraction; E/E': early transmitral filling (E) to early diastolic mitral annular velocity ( $E^{\prime}$ ) ratio; LA: left atrial; RA: right atrial; TAPSE: tricuspid annular plane systolic excursion; $\mathrm{PO}_{2}$ : oxygen tension; $\mathrm{PCO}_{2}$ : carbon dioxide tension; $\mathrm{SpO}_{2}$ : arterial oxygen saturation measured by pulse oximetry; $V^{\prime} \mathrm{O}_{2}$ : oxygen uptake; NT-proBNP: N-terminal pro-brain natriuretic peptide.

Apnoea/hypopnoea index (AHI) was elevated in two patients $\left(30\right.$ events $\cdot \mathrm{h}^{-1}$ and 60 events $\left.\cdot \mathrm{h}^{-1}\right)$. The mean AHI of the other patients was $3 \pm 2$ events $\cdot h^{-1}$. The maximum inspiratory mouth pressure was severely reduced to $3.3 \pm 1.9 \mathrm{kPa}$, and the respiratory load was $0.5 \pm 0.2 \mathrm{kPa}$.

Echocardiography showed signs of right ventricular dysfunction, but normal left ventricular systolic function. Early transmitral filling (E) to early diastolic mitral annular velocity $\left(E^{\prime}\right)$ ratio $\left(E / E^{\prime}\right)$ was $10 \pm 4$. Left atrial (LA) volume was slightly elevated. We calculated the right atrial (RA)/LA volume ratio and found a value of $1.8 \pm 0.6$ (online supplementary table 2 ).

Right heart catheterisation revealed severely elevated mPAP $(49 \pm 13 \mathrm{mmHg})$. In 14 patients pulmonary artery wedge pressure (PAWP) was $<15 \mathrm{mmHg}$, in three patients it was $>15 \mathrm{mmHg}$. However, all patients showed a diastolic pulmonary pressure gradient $>9 \mathrm{mmHg}(23 \pm 10 \mathrm{mmHg})$ and a transpulmonary vascular gradient $>12 \mathrm{mmHg}(38 \pm 12 \mathrm{mmHg})$. Cardiac index was normal. Heart rate at rest was $75 \pm 10$ per min and systemic blood pressure was 128/75 $\pm 18 / 10 \mathrm{mmHg}$.

The mPAP correlated positively with $\mathrm{BMI}$ and maximum night-time $\mathrm{CO}_{2}$. The pulmonary vascular resistance (PVR) correlated negatively with the maximum inspiratory mouth pressure (fig. 2$)$. There was a positive correlation of mPAP with alveolar-arterial oxygen tension difference $\left(P A-\mathrm{aO}_{2}\right)(\mathrm{R}=0.67 ; \mathrm{p}=0.049)$ and minute ventilation volume $\left(V^{\prime} \mathrm{E}\right) / \mathrm{CO}_{2}$ output $\left(V^{\prime} \mathrm{CO}_{2}\right)(\mathrm{R}=0.84 ; \mathrm{p}<0.01)$ and a negative correlation between $\mathrm{mPAP}$ and respiratory exchange rate (RER) at maximum exercise $(\mathrm{R}=-0.80 ; \mathrm{p}=0.01)$, as well as a negative correlation of PVR with end-tidal carbon dioxide tension $\left(\mathrm{PETCO}_{2}\right)$ at the anaerobic threshold 

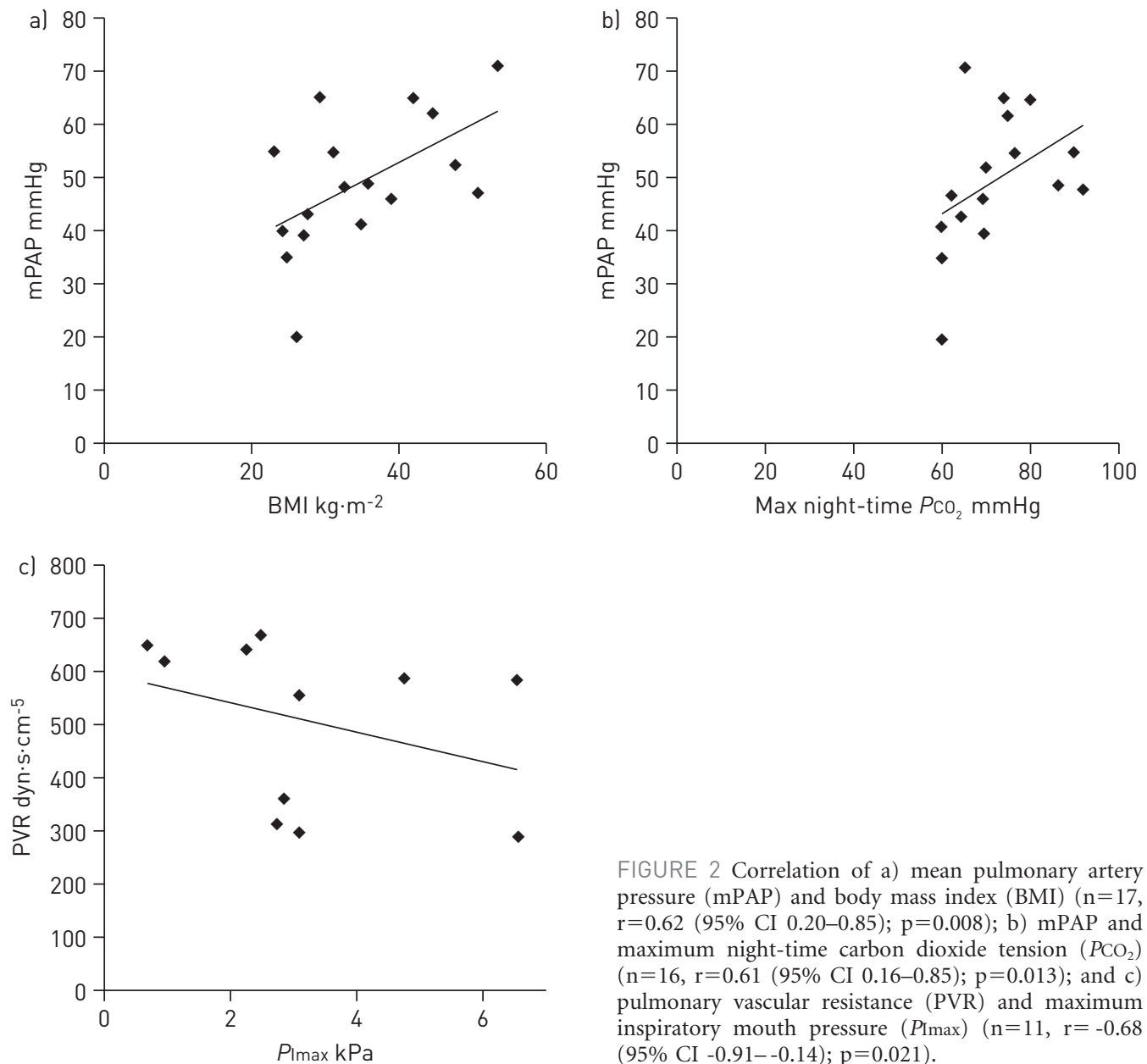

FIGURE 2 Correlation of a) mean pulmonary artery pressure (mPAP) and body mass index (BMI) $(\mathrm{n}=17$, $\mathrm{r}=0.62(95 \%$ CI $0.20-0.85) ; \mathrm{p}=0.008) ; \mathrm{b}) \mathrm{mPAP}$ and maximum night-time carbon dioxide tension $\left(\mathrm{PCO}_{2}\right)$ $(\mathrm{n}=16, \mathrm{r}=0.61(95 \%$ CI $0.16-0.85) ; \mathrm{p}=0.013)$; and $\mathrm{c})$ pulmonary vascular resistance (PVR) and maximum inspiratory mouth pressure $(P \operatorname{Imax})(\mathrm{n}=11, \mathrm{r}=-0.68$ $(95 \%$ CI $-0.91--0.14) ; \mathrm{p}=0.021)$

$(\mathrm{R}=-0.89, \mathrm{p}<0.01)$. There was no significant correlation of PAP with night-time oxygen saturation, daytime oxygen tension at rest or exercise, left ventricular function or static and dynamic pulmonary volumes (data not shown).

Peak oxygen uptake and maximum work rate at exercise were reduced. Mean 6-min walking distance (6MWD) was $303 \pm 134 \mathrm{~m}$. At baseline, we found normal values for heart rate reserve ( $33 \pm 19$ per $\mathrm{min}$ ), breathing reserve $(31 \pm 26 \%)$ and a RER of $0.97 \pm 0.12 . \mathrm{ETCO}_{2}$ was normal at rest and increased during exercise. $P \mathrm{~A}_{-} \mathrm{aO}_{2}$ was elevated (online supplementary table 3). Serum NT-proBNP levels were elevated, but not correlated to exercise capacity.

Maximum work rate was inversely correlated with mPAP, PVR (fig. 3) and $\mathrm{PA}-\mathrm{aO}_{2}(-0.72 ; \mathrm{p}=0.03)$ and $V^{\prime} \mathrm{E} /$ $V^{\prime} \mathrm{CO}_{2}(-0.87 ; \mathrm{p}<0.01)$. 6MWD was negatively correlated with mPAP (fig. 3) and positively correlated to $\mathrm{PETCO}_{2}$ at the anaerobic threshold $(0.83 ; \mathrm{p}=0.04)$.

\section{Effect of noninvasive positive-pressure ventilation}

NIPPV was performed as follows: inspiratory positive airway pressure $21 \pm 3$ mbar, expiratory positive airway pressure $5.5 \pm 1 \mathrm{mbar}$, inspiratory time $1.4 \pm 0.2 \mathrm{~s}$, frequency $20 \pm 3.5 \mathrm{~min}^{-1}$ and oxygen flow $2.9 \pm 1.9 \mathrm{~L} \cdot \mathrm{min}^{-1}$. Mean $\pm \mathrm{SD}$ duration of NIPPV was $5.4 \pm 2.6 \mathrm{~h}$. Table 1 shows the treatment effect of NIPPV at 3 month follow-up. Systolic, diastolic and mean PAP $(-18 \mathrm{mmHg} ; \mathrm{p}<0.001)$ and PVR $(-199$ mmHg; $\mathrm{p}<0.001)$ were decreased compared with pretreatment values (fig. 4); cardiac index and PAWP were not significantly changed. There was an improvement in exercise capacity, as indicated by a significant increase in maximum work rate (+18 W) and 6MWD (+66 m) (fig. 5).

There was no change in systemic blood pressure, heart rate, left ventricular ejection fraction and E/E' following NIPPV. The volume of the RA decreased from $97 \pm 57 \mathrm{~mL}$ to $65 \pm 34 \mathrm{~mL}(\mathrm{p}=0.002)$, whereas the volume of the LA increased from $57 \pm 33 \mathrm{~mL}$ to $77 \pm 45 \mathrm{~mL}(\mathrm{p}=0.002)$; the ratio of RA/LA volume decreased. There was no change in LV performance, measured by echocardiography, but RV function 

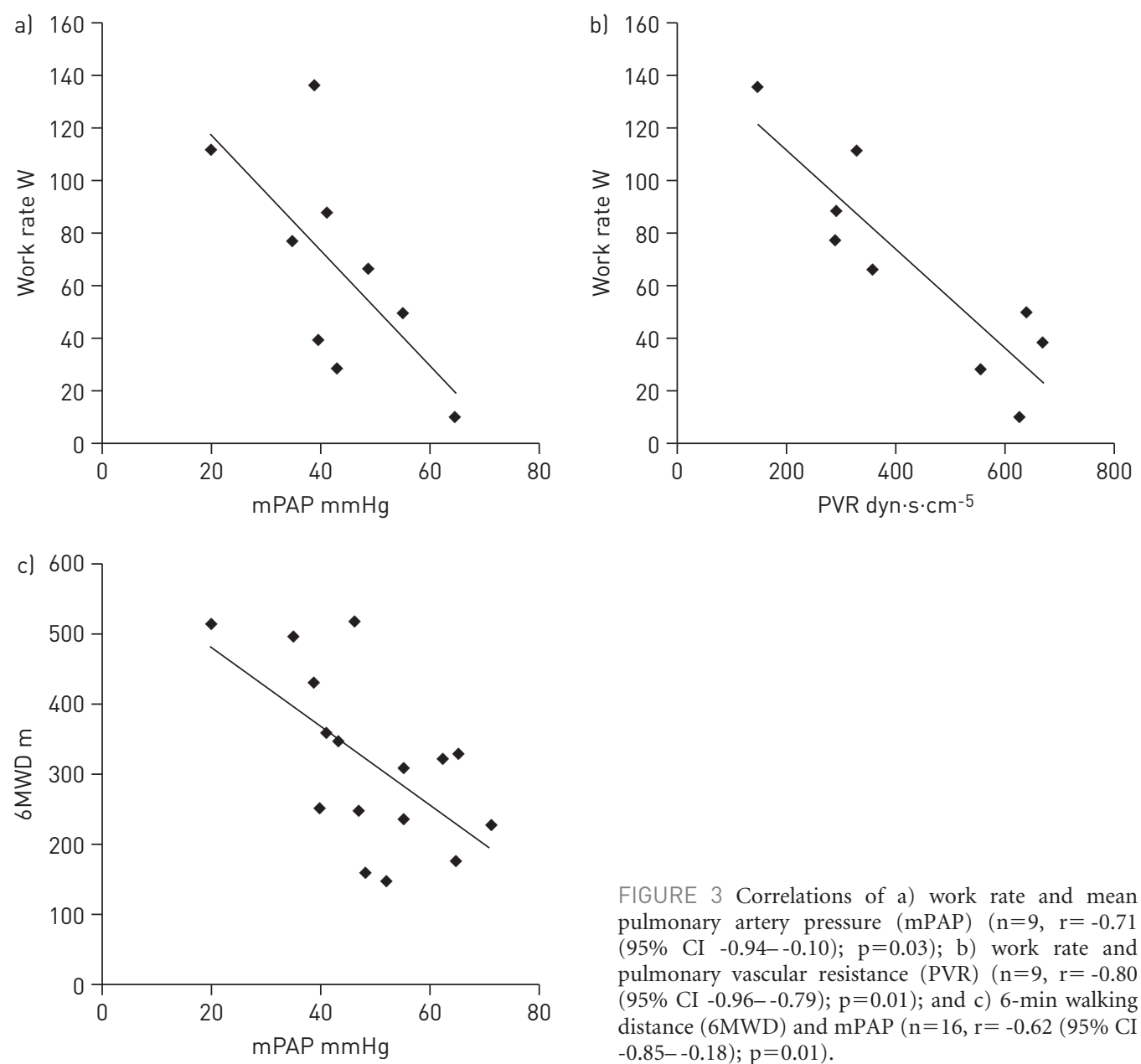

FIGURE 3 Correlations of a) work rate and mean
pulmonary artery pressure $(\mathrm{mPAP}) \quad(\mathrm{n}=9, \mathrm{r}=-0.71$
$(95 \%$ CI $-0.94--0.10) ; \mathrm{p}=0.03) ; \mathrm{b}) \quad$ work rate and
pulmonary vascular resistance (PVR) $(\mathrm{n}=9, \mathrm{r}=-0.80$
$(95 \% \mathrm{CI}-0.96--0.79) ; \mathrm{p}=0.01) ;$ and $\mathrm{c}) 6-\mathrm{min}$ walking
distance (6MWD) and mPAP $(\mathrm{n}=16, \mathrm{r}=-0.62(95 \%$ CI
$-0.85--0.18) ; \mathrm{p}=0.01)$.

improved after 3 months of NIPPV. Consistent with the improved cardiac function, serum levels of NTproBNP decreased significantly (table 1 and fig. 5). The haemodynamic improvement correlated positively with the increase in maximum work rate (fig. 6). Following NIPPV, FEV1 and VC increased, RV and intrathoracic gas volume decreased (not shown). $\mathrm{O}_{2}$ saturation and $\mathrm{CO}_{2}$ tension improved at night and daytime. There was no correlation between improved exercise capacity and changes in lung function (data not shown).

\section{Discussion}

To our knowledge, this is the first study to demonstrate a severe negative association between $\mathrm{PH}$ and exercise capacity in patients with alveolar hypoventilation and preserved cardiac index. The findings strongly support positive treatment effects of NIPPV on haemodynamics and functional capacity in these patients.

All patients showed hypoventilation with night-time and daytime hypercapnia and hypoxaemia. 12 patients were obese and fulfilled the criteria of OHS [33].

The mean mPAP of our cohort was much higher than previously reported $[1,5,28]$. These patients could represent a specific phenotype of severe $\mathrm{PH}$ associated with hypoventilation that is different from the majority of patients with hypoventilation. In obese patients, histological findings indicating $\mathrm{PH}$ seemed to be more frequent than the prevalence of PH reported in clinical studies [12]. Right heart catheterisation has not been routinely carried out in other studies dealing with $\mathrm{PH}$ and alveolar hypoventilation. Recently, MARIK et al. [1] provided a detailed analysis of patients with OHS, but did not measure haemodynamics invasively. Since echocardiography is difficult to perform in obese patients, the noninvasive approach is prone to underestimate both prevalence and severity of $\mathrm{PH}$ in these patients. Moreover, the higher number of patients with severe $\mathrm{PH}$ in our study might be due, in part, to selection bias, as we studied patients who were referred with suspected $\mathrm{PH}$ for evaluation and treatment. 

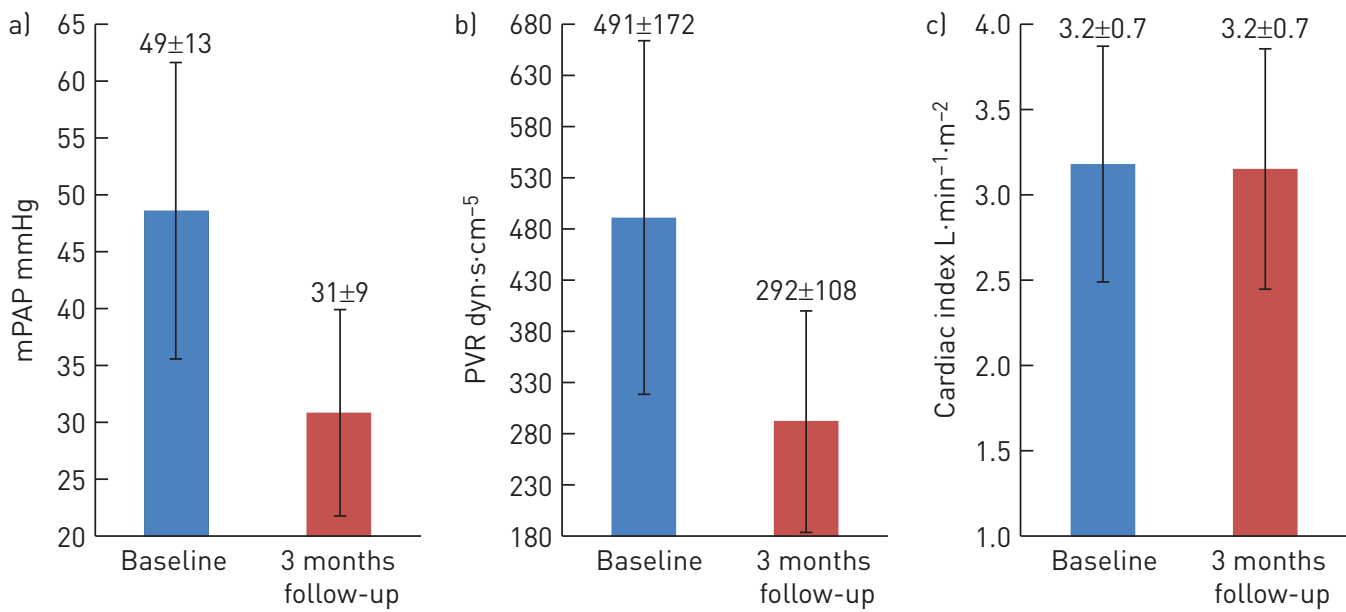

FIGURE 4 Changes in haemodynamic parameters after 3 months of noninvasive positive-pressure ventilation. a) Change in mean pulmonary artery pressure (mPAP), $n=16 ; \mathrm{p}<0.001$. b) pulmonary vascular resistance (PVR), $n=16 ; \mathrm{p}<0.001$. c) Change in cardiac index, $\mathrm{n}=15 ; \mathrm{p}=0.807$.

In an autopsy study, HAQUE et al. [12] found histological features of pulmonary arterial and pulmonary venous hypertension in $72 \%$ of obese patients compared with only $26 \%$ and $6 \%$ of nonobese controls. In our study, all but one patient underwent right heart catheterisation. Although mitral flow pattern might reflect a type 1 diastolic dysfunction, LA area was normal and LA volume was only slightly elevated [35]. Most of our patients had evidence for severe pre-capillary PH. Only three patients had PAWP >15 mmHg; however, pulmonary artery mean-to-capillary wedge pressure and pulmonary artery diastolic-to-capillary wedge pressure gradients were severely elevated, reflecting a relevant pre-capillary component of $\mathrm{PH}$ [36].

Systemic blood pressure at rest was normal and, despite severely elevated mPAP, patients responded with an increase in systolic blood pressure during exercise.

In patients with PAH and vasculopathy, cardiac index decreases with progressive disease [37]. In our cohort with severe $\mathrm{PH}$ and alveolar hypoventilation, cardiac index was normal or slightly elevated, which we interpret as a compensation for hypoventilation, ventilatory failure and hypercapnic hypoxia. Hypoventilation can occur in the context of a variety of disorders $[5,6,28]$, but it is still unclear how hypoventilation and $\mathrm{PH}$ develop. In our study, the majority of patients did not have a sleep-related breathing disorder. Only two patients (AHI 30 events $\cdot \mathrm{h}^{-1}$ and 60 events $\cdot \mathrm{h}^{-1}$ ) presented with severe sleep apnoea syndrome, indicating that OHS is not inevitably associated with sleep apnoea.
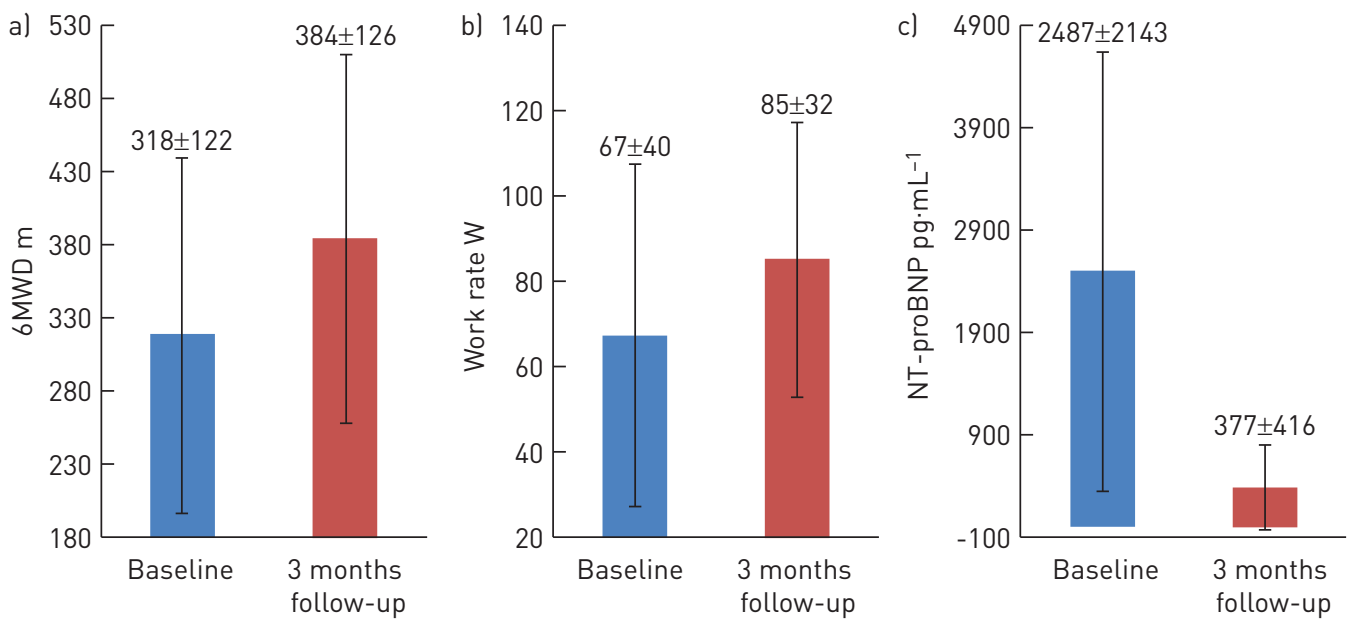

FIGURE 5 Changes to exercise capacity and N-terminal pro-brain natriuretic peptide (NT-proBNP) levels after 3 months of noninvasive positive-pressure ventilation. a) Change in 6-min walking distance (6MWD), $n=16 ; p=0.008$. b) Change in work rate, $n=9 ; p=0.028$. c) Change in NT-proBNP serum concentration, $n=13 ; p=0.001$. 
FIGURE 6 Correlation between change $(\Delta)$ in mean pulmonary artery pressure (mPAP) and change in maximum work rate after 3 months of noninvasive positivepressure ventilation. $\mathrm{n}=8, \mathrm{R}=-0.75(95 \%$ CI -0.952- -0.096); $\mathrm{p}=0.031$.

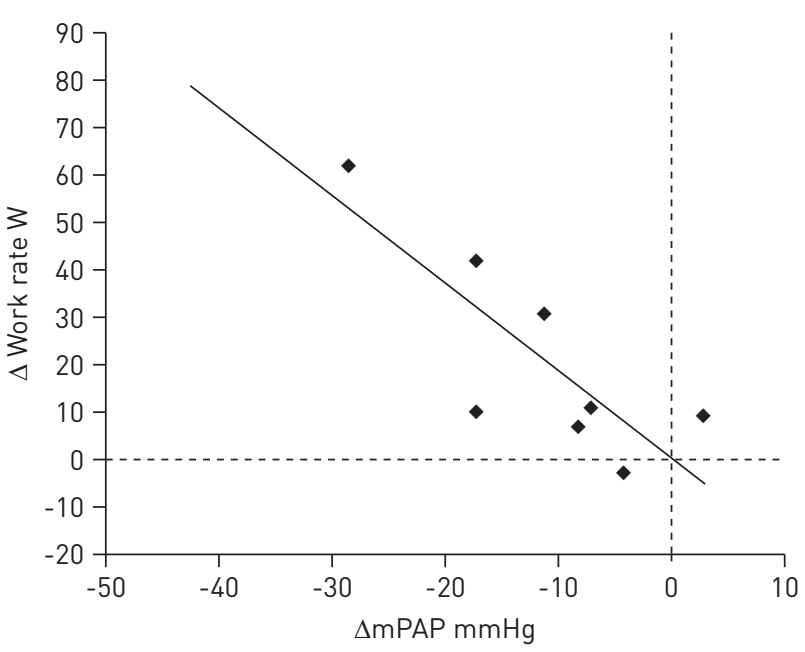

Five patients had COPD alone, three more had both COPD and OHS, resulting in an overall reduction of FEV1 and VC in our cohort. Reduced lung volumes may have been affected by reduced strength of breathing. Compared with published data for healthy cohorts, the patients in our study had reduced maximum inspiratory mouth pressure as a sign of disturbed respiratory muscle strength and elevated respiratory load [30]. We assume that hypercapnia and hypoxaemia were a consequence of hypoventilation.

We found an inverse correlation between PVR and maximum inspiratory mouth pressure. Reduced strength of breathing might be a cofactor for hypoventilation, which was associated with $\mathrm{PH}$ in our patients. Conversely, it is conceivable that in patients with severe $\mathrm{PH}$, respiratory muscle function is altered leading to reduced inspiratory mouth pressure as described by MEYER et al. [38].

The positive correlation of mPAP with $\mathrm{BMI}$ and night-time $\mathrm{CO}_{2}$ tension, but not with oxygen tension, lung volumes or left ventricular function suggest that $\mathrm{PH}$ was driven by BMI and hypercapnic vasoconstriction.

Due to the preserved cardiac index, it was unclear whether PH has a functional impact on patients with alveolar hypoventilation. Our study subjects had a marked impairment of functional capacity as shown by reduced $6 \mathrm{MWD}$, maximum work rate and maximum oxygen uptake. Since heart rate and breathing reserve were normal, our patients were not affected by cardiac or ventilatory limitation in the strictest sense. However, in patients with hypoventilation, breathing reserve has to be interpreted with caution. $P \mathrm{~A}-\mathrm{aO} \mathrm{O}_{2}$ was elevated, reflecting a limitation in gas exchange. We noticed high $V^{\prime} \mathrm{E} / V^{\prime} \mathrm{CO}_{2}$ slope was associated with lower $V^{\prime} \mathrm{CO}_{2}$ and RER, probably reflecting inefficient ventilation, which may have contributed to earlier termination of exercise and reflect poor respiratory function. We found a negative correlation between mPAP and work rate or 6MWD (fig. 4), indicating the importance of pulmonary haemodynamics for normal exercise capacity. However, low RER and increasing PETCO2 under exercise reveals that this specific cohort is different from patients with $\mathrm{PAH}$, i.e. our observations concerning the physiology on exercise are compatible with respiratory rather than haemodynamic limitation.

Although correlation does not prove causality, the fact that NIPPV was associated with a significant decrease in mPAP, which then correlated with an increase in maximum work rate, suggests that $\mathrm{PH}$ can have a substantial functional impact on patients with severe $\mathrm{PH}$ due to alveolar hypoventilation despite having normal cardiac index.

The cardiopulmonary exercise testing was carried out by nine patients. This was not due to selection bias, but it merely reflects that many of these severely ill patients are unable to perform cardiopulmonary exercise testing due to morbid obesity or severity of disease.

Although our study population had normal cardiac index and normal systolic left ventricular function, the patients showed echocardiographic signs of right ventricular dysfunction and elevated serum NT-proBNP levels. NT-proBNP levels did not correlate with $6 \mathrm{MWD}$, maximum work rate and cardiac index, but the levels still indicate a poor prognosis according to the published literature. Patients with obesity hypoventilation have increased mortality, as shown by several reports [1, 24, 39], and NT-proBNP levels seem to have a prognostic impact on PAH $[40,41]$. This argues for a possible role of NT-proBNP serum levels as a biomarker for patients with alveolar hypoventilation and needs to be explored in a prospective trial.

To our knowledge, this is the first report about the effect of NIPPV on haemodynamics and exercise capacity in a cohort of obese patients. The high mortality rates of patients with OHS and PH underscore the need for 
early and effective treatment [1]. For PH secondary to structural lung disease and ventilatory disorders, current treatment guidelines recommend focusing on management of the underlying disease [13, 14]. Despite these recommendations, it is still unclear whether this will improve $\mathrm{PH}$ or not. In our cohort, after 3 months NIPPV therapy, PAP and PVR decreased significantly $(\mathrm{p}<0.001)$, without affecting cardiac index and PAWP.

Interestingly, following NIPPV, the RA volume decreased while LA volume increased. Not surprisingly, this resulted in a decrease of the RA/LA volume ratio. These findings suggest that NIPPV decreased RA pressure as a consequence of improving PAP and PVR. The reduction of the RA volume then allows improved filling of LA.

Moreover, we found an improvement in 6MWD and maximum work rate. Interestingly, decreased mPAP correlated with increased maximum work rate under exercise. There was no correlation to daytime and night-time blood gases, underscoring the relevance of pulmonary haemodynamics for exercise capacity in this patient group. Patients with poor compliance to NIPPV (using it on $<50 \%$ of nights and for $<4$ h. night ${ }^{-1}, \mathrm{n}=5$ ) did not show an improvement in PAP and functional capacity, further supporting an overall benefit of NIPPV in these patients.

Our study is limited by a relatively small number of subjects and the single-centre observational design. However, the robustness of the data, including the fact that $\mathrm{PH}$ was determined by right heart catheterisation, allows us to postulate that NIPPV can improve haemodynamics and functional capacity in patients with $\mathrm{PH}$ due to alveolar hypoventilation. It should be noted that the increase in 6MWD in our study was higher than treatment effects reported in studies with vasoactive drugs for PAH [42-45].

\section{Conclusion}

The present study shows an association between the elevated PAP and reduced exercise capacity of patients with alveolar hypoventilation and severe daytime PH despite preserved CI. In these patients the use of NIPPV was associated with improved daytime haemodynamics and functional capacity. A larger prospective study should be initiated to confirm these data.

\section{Acknowledgements}

We thank S. Karl (Institute of Mathematics, University of Würzburg, Würzburg, Germany) for statistical support during this study.

\section{References}

1 Marik PE, Desai H. Characteristics of patients with the "malignant obesity hypoventilation syndrome" admitted to an ICU. J Intensive Care Med 2013; 28: 124-130.

2 Bradley TD, Rutherford R, Grossmann RF, et al. Role of daytime hypoxemia in the pathogenesis of right heart failure in the obstructive sleep apnea syndrome. Am Rev Respir Dis 1985; 131: 835-839.

3 Hawrylkiewicz I, Sliwiński P, Górecka D, et al. Pulmonary haemodynamics in patients with OSAS or an overlap syndrome. Monaldi Arch Chest Dis 2004; 61: 148-152.

4 Fletcher EC, Schaaf JM, Miller J, et al. Long-term cardiopulmonary sequelae in patients with sleep apnea and chronic lung disease. Am Rev Respir Dis 1987; 135: 525-533.

5 Kessler R, Chaouat A, Schinkewitch P, et al. The obesity-hypoventilation syndrome revisited: a prospective study of 34 consecutive cases. Chest 2001; 120: 369-376.

6 Sugerman HJ, Baron PL, Fairman RP, et al. Hemodynamic dysfunction in obesity hypoventilation syndrome and the effects of treatment with surgically induced weight loss. Ann Surg 1988; 207: 604-613.

7 Zielínski J. Effects of intermittent hypoxia on pulmonary haemodynamics: animal models versus studies in humans. Eur Respir J 2005; 25: 173-180.

8 Fletcher EC, Luckett RA, Miller T, et al. Exercise hemodynamics and gas exchange in patients with chronic obstruction pulmonary disease, sleep desaturation, and a daytime $\mathrm{PaO}_{2}$ above 60 mmHg. Am Rev Respir Dis 1989; 140: 1237-1245.

9 Chaouat A, Weitzenblum E, Kessler $\mathrm{R}$, et al. Sleep related $\mathrm{O}_{2}$ desaturation and daytime pulmonary hemodynamics in COPD patients with mild hypoxaemia. Eur Respir J 1997; 10: 1730-1735.

10 Lloyd TC Jr. Influence of blood pH on hypoxic pulmonary vasoconstriction. J Appl Physiol 1966; 21: 358-364.

11 McGuire M, Bradford A. Chronic intermittent hypercapnic hypoxia increases pulmonary arterial pressure and haematocrit in rats. Eur Respir J 2001; 18: 279-285.

12 Haque AK, Gadre S, Taylor J, et al. Pulmonary and cardiovascular complications of obesity: an autopsy study of 76 obese subjects. Arch Pathol Lab Med 2008; 132: 1397-1404.

13 Galiè N, Hoeper MM, Humbert M, et al. Guidelines for the diagnosis and treatment of pulmonary hypertension: the Task Force for the Diagnosis and Treatment of Pulmonary Hypertension of the European Society of Cardiology (ESC) and the European Respiratory Society (ERS), endorsed by the International Society of Heart and Lung Transplantation (ISHLT). Eur Heart J 2009; 30: 2493-2537.

14 Hoeper MM, Andreas S, Bastian A, et al. Pulmonary hypertension due to chronic lung disease: updated Recommendations of the Cologne Consensus Conference 2011. Int J Cardiol 2011; 154: Suppl. 1, S45-S53.

15 Zieliński J, Tobiasz M, Hawrylkiewicz I, et al. Effects of long-term oxygen therapy on pulmonary hemodynamics in COPD patients: a 6-year prospective study. Chest 1998; 113: 65-70.

16 Masa JF, Celli BR, Riesco JA, et al. Noninvasive positive pressure ventilation and not oxygen may prevent overt ventilatory failure in patients with chest wall diseases. Chest 1997; 112: 207-213. 
17 Sugerman HJ, Fairman RP, Sood RK, et al. Long-term effects of gastric surgery for treating respiratory insufficiency of obesity. Am J Clin Nutr 1992; 55: Suppl. 2, 597s-601s.

18 Mokhlesi B, Tulaimat A, Evans AT, et al. Impact of adherence with positive airway pressure therapy on hypercapnia in obstructive sleep apnea. J Clin Sleep Med 2006; 2: 57-62.

19 Sforza E, Krieger J, Weitzenblum E, et al. Long-term effects of treatment with nasal continous positive airway pressure on daytime lung function and pulmonary hemodynamics in patients with obstructive sleep apnea. Am Rev Respir Dis 1990; 141: 866-870.

20 Masa JF, Celli BR, Riesco JA, et al. The obesity hypoventilation syndrome can be treated with noninvasive mechanical ventilation. Chest 2001; 119: 1102-1107.

21 Heinemann F, Budweiser S, Dobroschke J, et al. Non-invasive positive pressure ventilation improves lung volumes in the obesity hypoventilation syndrome. Respir Med 2007; 101: 1229-1235.

22 Piper AJ, Sullivan CE. Effects of short-term NIPPV in the treatment of patients with severe obstructive sleep apnea and hypercapnia. Chest 1994; 105: 434-440.

23 de Lucas-Ramos P, de Miguel-Díez J, Santacruz-Siminiani A, et al. Benefits at 1 year of nocturnal intermittent positive pressure ventilation in patients with obesity-hypoventilation syndrome. Respir Med 2004; 98: 961-967.

24 Pérez de Llano LA, Golpe R, Ortiz Piquer M, et al. Short-term and long-term effects of nasal intermittent positive pressure ventilation in patients with obesity-hypoventilation syndrome. Chest 2005; 128: 587-594.

25 Chouri-Pontarollo N, Borel JC, Tamisier R, et al. Impaired objective daytime vigilance in obesity-hypoventilation syndrome: impact of noninvasive ventilation. Chest 2007; 131: 148-155.

26 Redolfi S, Corda L, La Piana G, et al. Long-term non-invasive ventilation increases chemosensitivity and leptin in obesity-hypoventilation syndrome. Respir Med 2007; 101: 1191-1195.

27 Han F, Chen E, Wei H, et al. Treatment effects on carbon dioxide retention in patients with obstructive sleep apnea-hypopnea syndrome. Chest 2001; 119: 1814-1819.

28 Schönhofer B, Barchfeld T, Wenzel M, et al. Auswirkungen der intermittierenden Selbstbeatmung auf die pulmonale Hypertonie bei chronisch ventilatorischer Insuffizienz [Effect of intermittent ventilation on pulmonary hypertension in chronic respiratory failure]. Pneumologie 1999; 53: Suppl. 2, S113-S115.

29 Quanjer PH, Tammeling GJ, Gotes JE, et al. Lung volumes and forced ventilatory flows. Eur Respir J 1993; 6: Suppl. $16,5-40$.

30 Koch B, Schäper C, Ittermann T, et al. Reference values for respiratory pressures in a general adult population results of the Study of Health in Pomerania (SHIP). Clin Physiol Funct Imaging 2010; 30: 460-465. ATS Statement: guidelines for the six-minute walk test. Am J Respir Crit Care Med 2002; 166: 111-117. ATS/ACCP Statement on cardiopulmonary exercise testing. Am J Respir Crit Care Med 2003; 167: 211-277.

Sleep-related breathing disorders in adults: recommendations for syndrome definition and measurement techniques in clinical research. The report of an American Academy of Sleep Medicine Task Force. Sleep 1999; 22: 667-689.

34 Windisch W, Brambring J, Budweiser S, et al. Nichtinvasive und invasive Beatmung als Therapie der chronischen respiratorischen Insuffizienz. S2-Leitlinie herausgegeben von der Deutschen Gesellschaft fur Pneumologie und Beatmungsmedizin e. V. [Non-invasive and invasive mechanical ventilation for treatment of chronic respiratory failure. S2-Guidelines published by the German Medical Association of Pneumology and Ventilatory Support]. Pneumologie 2010; 64: 207-240.

35 Lang RM, Bierig M, Devereux RB, et al. Recommendations for chamber quantification. Eur J Echocardiogr 2006; 7: 79-108.

36 Naeije R, Vachiery JL, Yerly P, et al. The transpulmonary pressure gradient for the diagnosis of pulmonary vascular disease. Eur Respir J 2013; 41: 217-223.

37 D'Alonso GE, Barst RJ, Ayres SM, et al. Survival in patients with primary pulmonary hypertension. Results from a national prospective registry. Ann Intern Med 1991; 115: 343-349.

38 Meyer FJ, Lossnitzer D, Kristen AV, et al. Respiratory muscle dysfunction in idiopathic pulmonary arterial hypertension. Eur Respir J 2005; 25: 125-130.

39 Nowbar S, Burkart KM, Gonzales R, et al. Obesity-associated hypoventilation in hospitalized patients: prevalence, effects, and outcome. Am J Med 2004; 116: 1-7.

40 Fijalkowska A, Kurzyna M, Torbicki A, et al. Serum N-terminal brain natriuretic peptide as a prognostic parameter in patients with pulmonary hypertension. Chest 2006; 129: 1313-1321.

41 Nickel N, Golpon H, Greer M, et al. The prognostic impact of follow-up assessments in patients with idiopathic pulmonary arterial hypertension. Eur Respir J 2012; 39: 589-596.

42 Galiè N, Ghofrani HA, Torbicki A, et al. Sildenafil citrate therapy for pulmonary arterial hypertension. $N$ Engl $J$ Med 2005; 353: 2148-2157.

43 Galiè N, Rubin LJ, Hoeper MM, et al. Treatment of patients with mildly symptomatic pulmonary arterial hypertension with bosentan (EARLY study): a double-blind, randomized controlled trial. Lancet 2008; 371; 2093-2100.

44 Galiè N, Olschewski H, Oudiz RJ, et al. Ambrisentan for the treatment of pulmonary arterial hypertension: results of the ambrisentan in pulmonary arterial hypertension, randomized double-blind, placebo-controlled multicenter efficacy (ARIES) study 1 and 2. Circulation 2008; 117: 3010-3019.

45 Galiè N, Brundage BH, Ghofrani HA, et al. Tadalafil therapy for pulmonary arterial hypertension. Circulation 2009; 119: 2894-2903. 